\title{
Smart Dustbin for Waste Management
}

\author{
W. A. L. Gayanthika, G. K. C. D. Maduranga, A. I. S. Silva, S. D. H. S. Wikramarathne, and R. M. I. S. \\ Ranasinghe
}

\begin{abstract}
Sri Lanka is facing urbanization with the impact of globalization, which has results in an increase of needs and wants of people and increasing living standards of people tremendously. Urbanization directly contributes to waste generation, and unscientific waste handling causes health hazards and urban environment degradation. The failure to address this escalating problem in a timely manner resulted in unsanitary eye sores and the degradation of wetlands, coastline, rivers and other streams which become dumping sites for plastic polythene and other mixed waste.
\end{abstract}

Index Terms-Eco-points, RFID, smart dustbin, waste categorizing.

\section{INTRODUCTION}

Waste Management is a critical process of a country. It affects almost all the sections of the country such as economy, culture, health, life style and life standard of people. Waste management intends to reduce adverse effects of waste on the above areas. [1] With the rapid growth of Sri Lankan population, the waste generation is also increasing. Statistics from the Ministry of Environment revealed that the average waste generation in the country stands at 6,400 tons per day of which only 2,800 tons are collected by the local authorities. The remaining 3,600 tons of solid waste are dumped in roadsides, water bodies, and low lands, causing serious health and environmental threats. [2] According to the existing process, government let the households and other entities to categorize their waste by themselves before it collect by collectors. It is not a successful system because there is no any motivational factor to the households and entities to categorize the garbage. For this process to be success there should be a legal and regulatory framework that relates to waste management encompassing guidance on recycling also.To dump garbage in a proper way or to recycle them, first the waste has to be categorized. It can be done in two ways.

\section{- Categorizing waste in a center after collection}

In this method first the waste is collected and brought in to a centre, then the waste is categorised manually as plastics, paper, glass, metal etc. This method consumes lot of labour,

Manuscript received October 15, 2018; revised January 13, 2019.

W. A. L. Gayanthika, S. D. H. S. Wikramarathne, and R. M. I. S. Ranasingha are with the Department of Computer Science and Technology, Uva Wellassa University, Badulla, Sri Lanka (e-mail: lakshani0915@gmail.com, harshisd@gmail.com, iranthiranasinghe@gmail.com).

G. K. C. D. Maduranga is with the Auxenta (pvt) Ltd of Sri Lanka, Sri Lanka (e-mail: cdm829@gmail.com)

A. I. S. Silva is with the department of Marketing of Asia Broadcasting Corporation Private Limited, Sri Lanka (e-mail: irusha.sandeepa@gmail.com). time and money.

- Categorizing waste at the moment they are collecting

This method is much different from above. In this method, the waste is categorised before they collected. For this the governments/organizations have given the public the different dustbins for different categories. So, the waste can be collected as categories under this method. This method has high initial cost than the 1st method, but this method is effective and efficient which also saves cost on excess labour, time and money spent on the 1st method.

As a developing country, Sri Lanka still doesn't have a proper waste management process. The current process followed by the government is dumping garbage in to different sites like Meethotamulla. This causes many problems like spread of diseases, negative impact on economy, environment pollution as there is no proper recycling process and regulations. The collected waste is brought in to a centre, and the waste is categorized by labourers. This process incurs excess labour costs, time and money for the municipal council. This method is not a very effective method because practically it is hard to categorize and maintain tons of waste in a waste collection centre regularly. The implemented system provides a solution for these interconnected problems. The primary objective of this research project is to provide an effective and efficient methodology to categorize the waste before waste collection happens. Also, motivate people to dump garbage in to dustbins in a proper way.

\section{LITERATURE REVIEW}

According to the research "Quantitative Analysis of Spatial Pattern of Dustbins and its Pollution in Dhaka City--A GIS Based Approach", the quantitative analysis has been made between existing dustbins and their serving population. According to the study, using average nearest neighbour functions of GIS, spatial distribution of dustbins in some areas of Dhaka City was conducted. When considering the spatial circulation of the current dustbins, it has appeared to be mainly in clustered pattern. As the next step, an optimal number of additional dustbins were calculated. It shows that the number of existing dustbins is insufficient in the study area Using spatial analyst functions of GIS, the extent of pollution caused by the existing dustbins was calculated. Then it is found that all the dustbins are burnt with wastes and it is causing pollution to the environment. [3]

Another research it explains about the smart bins have equipped with ultrasonic sensors. The level of the dustbin which being filled up will measure by these sensors. The container is divided into three levels. The sensors receive the 
relevant data regarding levels when every time the garbage crosses a level. Furthermore, by using GSM module, this data is sent to the garbage analyzer as instant message. According to the author there may be several disadvantages such as increasing cost of the dustbin. For example, if there are three different levels then three sensors has to be placed; one sensor for each level. Also rough action and usage of the user may cause damages to the sensors. But according to this paper the researchers have used only one level and one sensor [4].

Prof. R.M.Sahu and other authors have proposed an IoT-based Smart Garbage System (SGS) to reduce the amount of food waste. In an SGS, there are battery-based smart garbage bins (SGBs) which are using wireless mesh networks to exchange information with each other, collecting and analyzing the information for service provisioning is done through a router and server. Considering user convenience, the SGS includes various IoT skills. And also there are two types of operations of the SGBs: stand-alone operation and cooperation based operation which increase the energy efficiency and help to increases the battery lifetime. As a pilot project in Gangnam district, Seoul, Republic of Korea, the proposed SGS had been used for a one-year period. The pilot project has demonstrated that the normal amount of food waste can be decreased by $33 \%$. A framework has built by the authors, and it explains a Camera which will be set at each garbage collection point. Continuous snapshots of the garbage can will be taken by the camera. To compare the output of the camera and load sensor, a threshold level is set, and a microcontroller will help to make the comparison. Idea about the level of garbage in the "can" could be got after analyzing the image and weight of garbage can know from the load cell sensor. After processing the information controller checks if the threshold level is exceeded or not. This is convenient to use but economically may not be reliable. [5]

T. Sinha and other authors have designed a model for a 'Smart Dustbin' which indicates directly that the dustbin is filled to a certain level by the garbage and cleaning or emptying them is a matter of immediate concern. This prevents lumping of garbage in the roadside dustbin which ends up giving foul smell and illness to people. The design of the smart dustbin includes a single directional cylinder and an Arduino Uno. With this research, it is sending SMS to the Municipal Council that particular dustbin is to overflow. The circuit to power up the mechanical devices is also assembled to obtain the desired simulation. This dustbin is also designed to compress the garbage periodically thus preventing the unnecessary occupying of dustbin's space by light weighted but space occupying garbage particles like sponges, etc. [6]

\section{Methodology}

The system will calculate points according to the weight of the waste dump by the users and they will be rewarded with accordance to their points. The main purpose of the web application is to process and view the eco point collection system and maintain the user profiles. In the user profile is categorized under three categories as households, small businesses and large businesses. By accessing to their profiles they can view their points for waste of each category and their details. Recycle centers also can access to this web application, and they can see quantity of each category of waste and then they can put an order to buy those waste. This web application supports for indications. That means when a dustbin is full or reached to the maximum level this web application provides details to the admin whether it is full or not. As the system is designed for the general public, the system has been designed according to lifestyle of people. Sensors, RFID, GSM module are placed on that basis. To demonstrate the working system, a prototype was designed based on the structure. Fig. 1 shows the basic overview and the functional view of the designed dustbin.

The smart dustbin is used to handle the waste dumped by the users. The user is given a RFID tag and the user is identified by the given RFID tag. Once the user taps the RFID tag in the RFID reader, the lid of the dustbin is open by verifying the user ID through the database. Then the user can dump garbage in to the dustbin. When the user dumps the garbage in to the dustbin, the load-cell measure the weight of the waste dumped by the user and sends it to the database. If the dustbin is full, the ultrasonic sensor will detect it and send a text message to the collection center that the dustbin is full. In this system the researchers needed to make communication with the database which is hosted in a server. There are two communication methods available to use in this scenario. Those are Wired Communication and wireless communication. The researchers choose wireless communication method to transfer data to the database and retrieve data from the database. The wired communication methods like Ethernet is not practical with our Smart dustbin system, because those dustbins need to be mobile (movable). In the category of wireless communication, the researchers had to choose a device to make communication. The researchers identified two devices, WIFI module and GSM module.

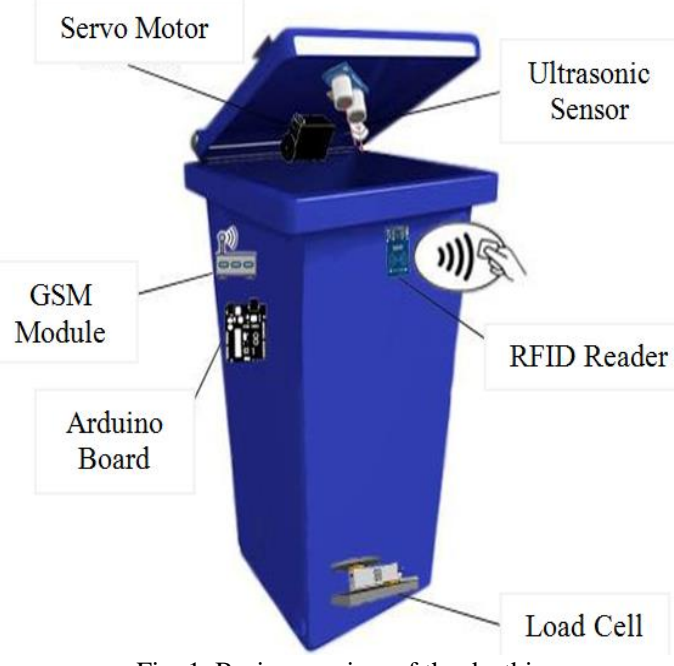

Fig. 1. Basic overview of the dustbin.

The Fig. 2 shows the functional view of the system. The dustbin lid will be opened, once the user taps his RFID tag in the RFID reader. Then the system will open the lid by validating the user ID from the database in the server using the GSM module. Before the lid opens the ultrasonic sensor 
will check the garbage level and if the dustbin is full the system will send a text message to the authority saying that dustbin is full and then opens the lid. Then user can dump the garbage in to the dustbin. The weight of the garbage will be measured by the load-cell and send to the database using GSM module.

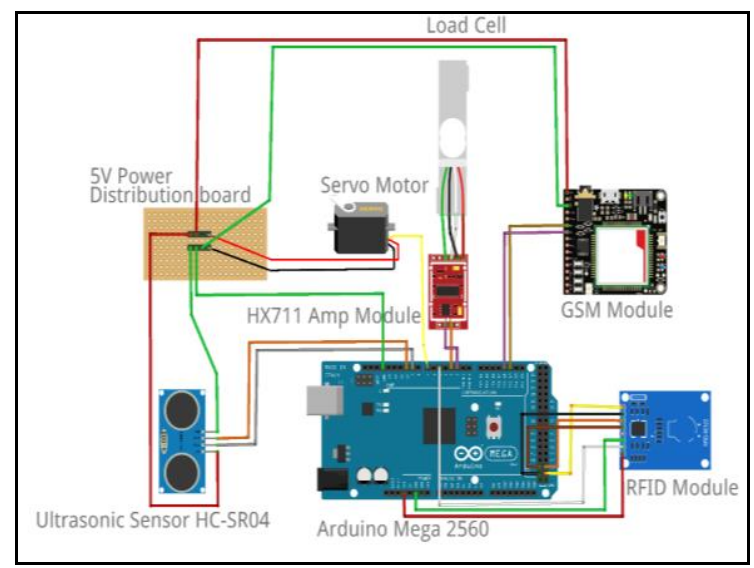

Fig. 2. The functional view of the system.

The researchers choose wireless communication method to transfer data to the database and retrieve data from the database. The wired communication methods like Ethernet are not practical with the smart dustbin system, because those dustbins need to be movable. The system developed module by module. The researchers Arduino Mega 2560 as our micro controller because it has 54 digital input/output pins (of which 15 can be used as PWM outputs), 16 analog inputs, 4 UARTs (hardware serial ports), a $16 \mathrm{MHz}$ crystal oscillator, a USB connection, a power jack, an ICSP header, and a reset button while Arduino UNO only has 14 digital input/output pins (of which 6 can be used as PWM outputs), 6 analog inputs, a $16 \mathrm{MHz}$ ceramic resonator, a USB connection, a power jack, an ICSP header, and a reset button. And we had to read data from several sensors and retrieve data using GSM module.

Configuring RFID reader was the first step. Then the GSM module was configured and enables the GPRS to communicate with the database and to pass data. After configuring GSM module, integrate both RFID and GSM module together through Arduino. This integration enables the system to validate the ID of the RFID tag from the database through the mobile network. As the next step, the servo motor to be operated to open the lid when valid user taps an RFID tag was setup. The servo motor was set up to rotate by 900 to open the lid. Then the ultrasonic sensor was programmed to detect the waste level of the dustbin. The distance of from sensor to upfront object is measured using the following formula.

Distance $=\frac{(\text { Speed of sound } * \text { time taken to return })}{2}$

Ultra-Sonic Sensor is used to measure distance. The sensor head emits a sonar ultrasonic wave at specific frequency and receives the wave reflected by bouncing back from the target. The sound travels through air about $344 \mathrm{~m} / \mathrm{s}$. The researchers can take the time taken by sound wave to return and multiply it by 344 meters to find the total round trip distance travel.
Round trip means the wave travel two times the distance to the object before it was detected by the sensor. It includes distance from sensor to object and object to sensor (after sound wave bounce off the object). If the ultrasonic detects objects at $90 \%$ top level of the dustbin, the system was programmed to send the text message to authority saying that dustbin is full and about to overflow using the GSM module.

The configuration of load cell was the last step, and the researchers had to calibrate the load cell to get the calibration factor value to convert strain electric value to weight and display the weight as output. The researchers use several objects which have a given weight to calibrate the load-cell. Load cell is a sensor which is used to measure the weight of objects. Load-cell is a transducer which converts force in to measurable electric output. It is basically a device that measures strain and then coverts force into electric energy which serves as a measurement. In the research the load-cell is used to measure the weight of the waste dump in to the dustbin.

Finally, all modules were integrated as a one system. The power was given to the modules separately, and GSM module was given a separate power line, the RFID and Load-cell was powered by the Arduino board, the ultrasonic sensor and servo motor was separately powered as a one module. Most of the system components use around 5V and RFID uses 3.3V. For the full functioning of the system approximately it is enough to have $500 \mathrm{~mA}$ to $700 \mathrm{~mA}$.

\section{RESUlts}

This research is covered categorizing waste, dispose garbage in a systematic manner, collecting garbage properly and recycling that garbage successfully. It is an interrelated solution for the current waste disposal problem. The researchers proposed an Arduino based smart dustbin to overcome above stated problems with related to waste management. A set of smart dustbins are assigned to certain number of households depending on their waste amount. The dustbin will be opened, once the user taps his RFID tag in the RFID reader. Then the system will open the lid by validating the user ID from the database in the server using the GSM module. Before the lid opens, the ultrasonic sensor will check the garbage level and if the dustbin is full the system will send a text message to the authority saying that dustbin is full and then opens the lid. Then user can dump the garbage in to the dustbin. The weight of the garbage will be measured by the load-cell and send to the database using GSM module. Finally, this system is having several advantages for the current waste disposal. It can motivate the people to categorize their waste with point rewarding system. And also, it helps to maintain the beauty of the country and make it attractive place to the public. The households and the Municipal Council can get financial benefits with this system.

\section{CONCLUSION}

The Smart Dustbin and point rewarding system concept which designed are an optimal solution for Municipal council 
to manage their waste collection in an efficient way. As the ineffective waste management is due to lack of methodology to categorize waste and collect them in an effective time schedule, the system designed will influence the people to categorize their waste by their own and the municipal council can collect the waste on a proper plan with the notifications they get from the smart dustbins when they are about to full and overflow. The Municipal council does not have to worry about the waste they are collected anymore. As the collected waste amounts in municipal council waste collection centers can be viewed by the recycling centers, the municipal council can sell most of the waste categories to those recycle centers as the wastes are properly categorized. The researchers hope this system will help to encourage people to categorize the waste. And also, the government can establish this system to overcome several problems such as waste categorizing, waste collecting, waste disposal, and waste recycling, etc.

\section{ACKNOWLEDGMENT}

Firstly, we would like to express our sincere gratitude to our supervisors Ms. S. D. H. S. Wikramarathne, Senior Lecturer of Department of Computer Science and Technology, Uva Wellassa University of Sri Lanka and R.M.I.S. Ranasingha the Lecturer of Department of Computer Science and Technology, Uva Wellassa University of Sri Lanka, for the continuous support, for their patience, motivation, and immense knowledge.

\section{REFERENCES}

[1] L. A. Guerrero et al., "Solid waste management challenges for cities in developing countries," Science Direct, vol. 33, issue 1, January 2013, pp. 220-232

[2] Towards a Waste-Free Sri Lanka. (2013). DailyFT Website. [Online]. Available:

http://www.ft.lk/special-report/towards-a-waste-free-sri-lanka/22-144 449)

[3] M. T. H. Shubho, M. T. Hassan, M. R. Hossain and M. N. Neema, "Quantitative analysis of spatial pattern of dustbins and its pollution in Dhaka city - A GIS based approach," Asian Transactions on Engineering, vol. 03, issue 04, September 2013, pp. 1-7.

[4] N. Sharma, N. Singha, and T. Dutta, "Smart bin implementation for smart cities," International Journal of Scientific \& Engineering Research, vol. 6, issue 9, September 2015, pp. 787-791.

[5] R. M. Sahu, A. Godase et al., "Garbage and street light monitoring system using internet of things," International Journal of Innovative Research in Electrical, Electronics, Instrumentation and Control Engineering, vol. 4, issue 4, April 2016.

[6] T. Sinha, K. M. Kumar, and P. Saisharan, "Smart dustbin," International Journal of Industrial Electronics and Electrical Engineering, ISSN: 2347-6982, vol. 3, issue 5, May 2015.

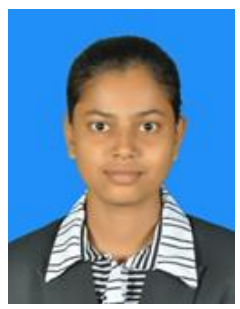

W. A. L. Gayanthika was born in city of Avissawella, Sri Lanka, on September 15, 1992. She obtained her special degree of bachelor of industrial information technology from University of Uva Wellassa University, Sri Lanka, 2017.

She is currently working as a demonstrator attached to the Department of Computer Science \& Technology of Uva Wellassa University of Sri Lanka. She published her first research abstract on smart dustbin with the web based point reward system for waste management in International Research Symposium of Uva Wellassa University of Sri Lanka (IRSUWU - 2017).

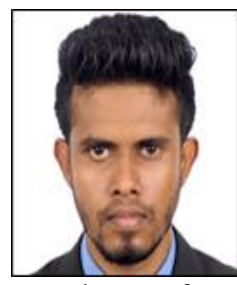

G. K. C. D. Maduranga was born in city of Galle, Sri Lanka, on August 29, 1993. He obtained his special degree of bachelor of industrial information technology from University of Uva Wellassa University, Sri Lanka, 2017. He is currently working as a software quality assurance engineer at Auxenta (pvt) Ltd of Sri Lanka. He published his first research abstract on smart dustbin with the web based point reward system for waste management in International Research Symposium of Uva Wellassa University of Sri Lanka (IRSUWU - 2017).

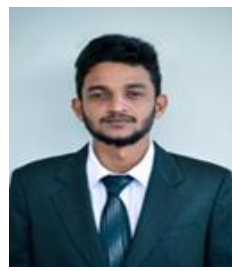

A. I. S. Silva was born in city of Kalutara, Sri Lanka, May 5, 1993. He obtained the special degree of bachelor of industrial information technology, University of Uva Wellassa University, Sri Lanka, 2017. He is working as a management trainee attached to the department of Marketing of Asia Broadcasting Corporation Private Limited. He published his first research abstract on smart dustbin with the web based point reward system for waste management in International Research Symposium of Uva Wellassa University of Sri Lanka (IRSUWU - 2017).

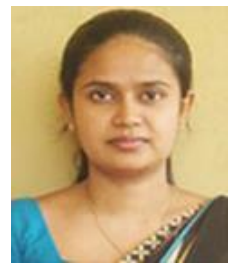

S. D. H. S Wickramarathna was born in city of Badulla, Sri Lanka, July 12, 1983. She obtained the master of science in computer science, Asian Institute of Technology, Thailand-2016; the honors degree of bachelor of science in information technology, University of Moratuwa, Sri Lanka-2009.

She is working as a senior lecturer attached to the Department of Computer Science \& Technology of Uva Wellassa University of Sri Lanka. Prior to that she worked as a SOFTWRE ENGINEER at Virtusa Pvt Ltd, Sri Lanka. Some of her interesting publications are as follows: 1) S.S.Fernando, S.D.H.S Wickramarathna, Sri Lankan Sign Language Tutor, International Conference on Business Innovation, August, 2018; 2) S.D.H.S Wickramarathna, C. Anuthariya, Ontology design and development for university admission in Sri Lankan Universities, SLAAI International Conference on Artificial Intelligence, December, 2017. 3) K.A.W.P Abesinghe and S.D.H.S Wickramarathna, Bone Crack Detector based on X-Ray using Fuzzy Logic and Neural Network, Annual Sessions of Sri Lanka Association for Artificial Intelligence, November, 2013.

Her current research interests are on ontological engineering, semantic web and linked data and intelligent recommender systems. Earlier she was interested more on artificial intelligence.

Mrs. Wickramarathna is a member of Institute of Electrical and Electronics Engineers association (IEEE) and a student counselor of Uva Wellassa University Women in Engineering Student Branch Affinity Group. Mrs. Wickramarathna has won the award of "Best AI project of the year 2017" in SLAAI International Conference on Artificial Intelligence.

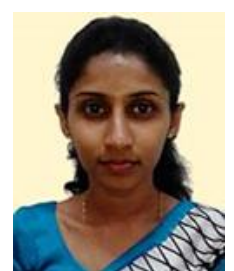

R. M. I. S. Ranasinghe was born in city of Rathnapura, Sri Lanka, April 11, 1990. She got the special degree of bachelor of industrial information technology, University of Uva Wellassa University, Sri Lanka, 2014

She is working as a lecturer probationary attached to the Department of Computer Science and Technology of Uva Wellassa University of Sri Lanka. Some of her publications are as follows: 1) Ranasinghe R.M.I.S. and Kartheeswaran, T. 2018. Trends and Development of Digital Marketing In Sri Lanka, 2nd Research Conference of Business Studies- 2018; 2) Weerasooriya, W.M.P.S., Iloshini,P.A.A. and Ranasinghe, R.M.I.S. 2017. Effective Awareness Framework for Better Password Security (BPS Awareness Framework) For Advanced Users. International Research Symposium of Uva Wellassa University of Sri Lanka (IRSUWU - 2017); 3) Jayathunga, D.P., Ranasinghe, R.M.I.S. and Iloshini, P.A.A. 2016. Multi-Agent-Based Secure Textual Communication. Kelaniya International Conference on Advances in Computing and Technology (KICACT - 2016).

Her current research interests are on IT-business intelligence, digital marketing and applied information systems. 